\title{
Corporeidade e ação nos processos de formação do eu
}

\author{
Pedro Salem \\ Nelson Ernesto Coelho Junior \\ Universidade de São Paulo
}

\begin{abstract}
Resumo
Parte-se da hipótese de que tanto os modos de constituição da subjetividade, quanto as teses epistemológicas sobre a formação do eu têm sofrido importantes mudanças nas últimas décadas. No plano das identidades pessoais, tal fato se expressa no atenuamento do ideário intimista, tradicionalmente centrado na idéia da vida mental como espaço privado e interior. No plano epistemológico, diferentes saberes vêm questionando a equivalência entre vida mental e interioridade psicológica e propondo descrições da origem do eu que incluam a dimensão da corporeidade e da ação. Considerando as noções de representação e de ação como eixos fundamentais para diferentes concepções da subjetividade, este artigo examina um modelo internalista do psiquismo, contrastando-o com outro que toma o eu como agente corporificado.
\end{abstract}

Palavras-chave: constituição do eu; psicanálise, psicologia do desenvolvimento; corporeidade; ação.

\begin{abstract}
Embodiment and action in the constitution of the self. This article is based on the assumption that the processes of the constitution of subjectivity as well as the epistemological thesis on the origins of the self have gone through important changes in the last decades. Regarding personal identities, this fact is expressed by the decreasing value of the idea that the mental life corresponds to a private and intimate psychic space. In the epistemological sphere, several disciplines have been challenging the equivalence between mental life and psychological interiority, and have been proposing new descriptions of the origins of the self that have been focusing the concepts of embodiment and action. Considering the notions of representation and action as main tools to account for different conceptions of subjectivity, this article examines an internalist model of the psychic life in contrast to another one that describes the self as an embodied agent.

Keywords: constitution of the self; psychoanalysis; developmental psychology; embodiment; action.
\end{abstract}

$\mathrm{P}$ arte significativa da literatura psicanalítica produzida na última década tem chamado a atenção para a importância que os novos sintomas corporais vêm ganhando na expressão geral dos quadros clínicos atuais. De fato, diversos autores têm apontado para o enfraquecimento da expressão cultural das formações sintomáticas privilegiadas por Freud em sua prática inicial - como os quadros eminentemente neuróticos, sejam obsessivos, fóbicos ou histéricos - se comparados à pregnância dos chamados distúrbios corpóreos ou da imagem do eu. Mesmo se já identificados e descritos desde o início do século $\mathrm{XX}$, um considerável consenso parece girar em torno de um mesmo denominador: seja pela via dos transtornos da imagem corporal, seja pelos modos crescentemente testemunhados de abuso na exploração das sensações corporais, tais quadros têm ganhado crescente visibilidade junto à nosologia psicanalítica tradicional ${ }^{1}$.

Se considerarmos a estreita relação entre manifestações psicopatológicas e os contextos sociais, econômicos, políticos e culturais nos quais ganham forma, essa mudança parece expressiva de um fenômeno mais amplo, qual seja, as profundas transformações dos modos de constituição da subjetividade contemporânea. Pressupondo que a realidade sociocultural afeta a subjetividade ao gerar ideais de felicidade, repertórios de conduta e a criação de jogos de linguagem que dão consistência ao imaginário social e individual de uma época, determinados autores têm indicado importantes alterações nesse cenário. Fundamentalmente, sugerem alguns estudiosos (Bezerra, 2002; Costa, 2004), assiste-se a um enfraquecimento do ideário intimista, que vem sendo progressivamente substituído pela construção de critérios corpóreos como a matriz básica para a formação das identidades pessoais.

A experiência da identidade pessoal no ocidente pode ser considerada o resultado da combinação dos elementos culturais providos principalmente por duas culturas modernas. Com efeito, foi essencialmente por meio do racionalismo universalista dos iluministas e do expressivismo singularizante dos românticos que, ao longo do século XVIII, fundaram-se as bases para o nascimento de uma forma subjetiva particular (Taylor, 1994). Caracterizada pela construção de identidades fundadas em atributos e sentimentos privados e pela problematização e 
exploração do repertório afetivo de condutas íntimas, o chamado homo psycologicus emergiu no bojo dessas duas manifestações culturais europeias (Figueiredo, 1999). Nesse contexto, interessa aqui salientar fundamentalmente dois fatores diretamente relacionados à experiência identitária moderna: o nascimento e a proliferação do sentido de interioridade psicológica, em torno do qual o homem passou a organizar sua experiência; e a noção de conflito psíquico, tomada como o centro normativo da formação subjetiva moderna. Tais aspectos expressam a passagem de um mundo no qual as determinações externas e coletivas que regiam a vida foram substituídas pela crença de que a fonte de verdade e sentido básico para a existência se ancora na própria interioridade do sujeito sendo, deste modo, passível de ser descoberta por um esforço de introspecção e mergulho em si mesmo.

O presente artigo, baseando-se no pressuposto de que o modelo psicanalítico da vida mental é tributário do ideário intimista, tenciona contrastá-lo com uma descrição da vida psíquica cujo referente fundamental encontra-se na ideia de ação e do eu como um agente corporificado. Pretende-se examinar a hipótese de que a experiência identitária moderna passa hoje por transformações profundas - marcadas pelo declínio da valorização de predicados mentais como base para as identidades pessoais - para, em seguida, recorrer a modelos da vida mental menos referidos à ideia de interioridade e que, por tal motivo, poderiam vir a fornecer elementos que contribuam para novas proposições psicanalíticas concernentes à constituição do eu.

\section{A psicanálise e o ideário intimista}

A psicanálise, pode-se afirmar, nasce imersa nesse ideário intimista. Influenciada pela tradição filosófica ocidental, que propagou o hábito de exploração dos estados anímicos humanos e das causas do sofrimento; pelo universo sociocultural e artístico dos séculos XVIII e XIX, que fomentou a crença de que nas profundezas da alma estaria oculta a fonte de valiosos conhecimentos sobre o indivíduo; e, por fim, pela tradição terapêutica moderna que deu origem a uma clínica voltada para o alívio do sofrimento físico e/ou mental, a psicanálise constituiuse como um saber e uma prática fundamentais no imaginário cultural da modernidade (Bezerra, 2002). Freud, informado por esse cenário geral, ajudou a aprofundar o valor cultural da interioridade, tendo elaborado uma concepção original da vida mental e um modo inédito de descrever e lidar com o sofrimento humano a partir da noção básica de que este é gerado por um conjunto de forças psíquicas em conflito que, se acessadas em sua origem, teriam a capacidade de atenuá-lo ou mesmo extingui-lo.

Ocorre que, como afirmado, o quadro histórico no qual a psicanálise nasceu vem sofrendo importantes transformações e vem se distanciando daquele que deu origem às suas concepções teóricas e seus instrumentos terapêuticos iniciais (Roudinesco, 2000). Diversos são os autores que, nas últimas décadas, têm orientado suas investigações para a detecção dessas mudanças, cujas inferências e análises alcançam um espectro consideravelmente amplo. Fatores como o aprofundamento das consequências do individualismo (Sennett, 1999), o surgimento de uma cultura de tons eminentemente narcísicos (Lasch, 1983), a entronização de modos de satisfação referidos às sensações corporais (Bauman, 1998) e a valorização do prazer e da autossatisfação individuais no tempo presente (Lipovetsky, 1983), aliados a mudanças nos âmbitos sociais, econômicos e políticos testemunhados mais intensamente a partir da segunda metade do século XX têm, por exemplo, sido apontados como fatores determinantes das configurações subjetivas observadas com maior frequência nas últimas décadas. Ademais, a crescente importância da dimensão corporal e a chamada "somatização da subjetividade" (Bezerra, 2002) também estariam contribuindo para a mudança em curso, alterando o repertório básico de condutas e valores sobre os quais são construídas as identidades pessoais. Ou seja, o sujeito sentimental, caracterizado pela valorização da interioridade psicológica como um espaço no qual estariam contidos pensamentos, desejos, crenças e intenções passíveis de uma atitude introspectiva e interpretativa, viria a conviver crescentemente com configurações subjetivas que se organizam na exterioridade visível da imagem corporal e no escrutínio e fruição das sensações físicas. Deixando de lado as regras sentimentais de outrora e o acesso à vida interior como um dos focos privilegiados para a construção dos ideais de eu, tais construções identitárias estariam sendo pautadas em repertórios de caráter menos intimista que, dentre outras consequências, tornariam a experiência subjetiva avessa à experiência de conflito interno e menos referida à sua dimensão privada e idiossincrática (Bezerra, 2002).

Esse processo de mudança na formação cultural dos ideais de eu vem, por sua vez, influenciando a evolução da teoria e da prática psicanalíticas. Se até meados da década de cinquenta a psicanálise ainda se constituía como uma disciplina fundamentalmente homogênea, dotada de uma identidade incontestável e despida de maiores divergências quanto a um conjunto partilhado de proposições básicas, esse cenário alterou-se significativamente desde então (Green, 2002). Já no final da primeira metade do século XX, alguns autores passaram a chamar a atenção da comunidade psicanalítica para a proliferação de quadros nosográficos que fugiam às descrições enunciadas por Freud, fato que promoveu o esforço de constituição de novos referenciais teóricos e instrumentos clínicos originais. As décadas subsequentes testemunharam a proliferação de descrições psicopatológicas que contrastavam com os sintomas tradicionais relacionados às histerias, fobias e obsessões como as principais manifestações da aflição psíquica dos pacientes, e o aprofundamento do estudo das psicoses, dos "distúrbios de caráter", das depressões, dos chamados casos e situações-limite assumiram posição importante na literatura psicanalítica. Paralelamente e articulada à ampliação do espectro diagnóstico psicanalítico, uma forte crítica dirigida a determinados elementos da metapsicologia freudiana e ao alcance clínico do método interpretativo também ganhou corpo no seio da psicanálise (Eagle, 1984). Se bem que, embora alguns autores contemporâneos a Freud tenham dedicado esforços ao exame de casos refratários ao método clássico de tratamento dos conflitos edipianos - baseados na associação livre do paciente, na atenção flutuante e na interpretação pelo analista do material inconsciente recalcado - é, com efeito, a partir da segunda metade do século XX que se acentuam as buscas por novos referenciais teóricos e por instrumentos clínicos alternativos à interpretação ${ }^{2}$. A perseguição pela renovação teórico-clínica da 
psicanálise observada desde então e intensificada nas últimas décadas pode em parte ser compreendida, sugere-se aqui, como o reflexo da mudança nos modos de constituição da subjetividade mais intensamente observados a partir da segunda metade do século XX. Os impasses clínicos atuais parecem expressar a experiência empírica de analistas que, ainda informados pela tipologia psicológica prevalente do sujeito sentimental, deparam-se com indivíduos aparentemente distantes do recurso narrativo que propalava o recuo à própria interioridade como a via régia para conferir sentido e alívio para os conflitos pessoais. Desse modo, ainda que as hipóteses construídas em torno das importantes alterações que marcaram o processo de formação da identidade nas últimas décadas não respondam integralmente pela crescente visibilidade de determinadas manifestações psicopatológicas observadas na atualidade, tampouco podem ser descartadas como fator significativo para a compreensão desse cenário geral. A patoplastia dos distúrbios corporais atuais parece, nesse contexto, um efeito imprevisto da valorização de predicados baseados em imagens e sensações corporais e do consequente declínio do vocabulário sentimental como fonte de doação de identidade.

\section{Constituição subjetiva e a metáfora da mente interior}

Os efeitos do enfraquecimento do valor cultural da interioridade psicológica não parecem, no entanto, restringir-se aos processos de constituição da identidade contemporânea. No plano conceitual e epistemológico, diferentes campos de saber vêm propondo reformulações à metáfora da mente interior e vêm igualmente questionando versões que atrelam a vida subjetiva aos recursos exclusivamente narrativos e simbólicos do sujeito. A equivalência entre vida mental e interioridade psicológica, ao menos no que concerne a perspectiva propugnada pelo pensamento cartesiano, vem encontrando fortes críticas no domínio da filosofia, da psicologia e, mais recentemente, das neurociências cognitivas. Questionando o fundamento solipsista do homem pressuposto por Descartes, diversos estudiosos têm formulado modelos da vida mental nos quais a dimensão ambiental, seja em sua manifestação física (objetos) ou social (outros), ocupa lugar de destaque. Com efeito, ao incluir a dimensão da alteridade na compreensão dos processos de formação do eu, buscam evitar as consequências epistemológicas do sujeito autocentrado concebido pelo cartesianismo e sua versão solipsista da vida mental. Ao tomar o eu como uma unidade autoconstituída e gerada independente da existência de um 'outro', o pensamento cartesiano não apenas conferiu à mente uma face fundamentalmente solitária, mas também tornou inexplicáveis as trocas e interações sociais, legando à filosofia o problema de responder a questão a respeito das possibilidades de conhecimento do outro e sua participação nos processos de formação do eu (Coelho Junior \& Figueiredo, 2003; Crossley, 2001).

A psicanálise, ao operar um "descentramento do sujeito" e fundar a ideia de que parte dos conteúdos mentais que lhe determinam escapa ao escopo da apreensão consciente, rompeu inquestionavelmente com as filosofias e psicologias da consciência derivadas do cartesianismo (Imbasciati, 2007). Por outro lado, guardou parte de sua influência ao propor uma visão mentalista e internalista da vida mental que, como afirmado, vem sendo amplamente questionada por correntes teóricas e experimentais de disciplinas que concorrem para a compreensão do psiquismo e de suas manifestações psicopatológicas. De modo geral, críticas à teoria da mente psicanalítica e à sua compreensão dos processos de constituição do eu - sejam elas internas ou externas à psicanálise - incidem fundamentalmente em dois aspectos: em primeiro lugar, afirma-se que os escritos freudianos, corroborando pressupostos cartesianos, teriam concebido um modelo do psiquismo de uma perspectiva solipsista da vida mental (Cavell, 2006; Fonagy, Gergely, Jurist, \& Target, 2005). Em seguida, as críticas precipitam-se sobre a compreensão psicanalítica acerca da gênese do psiquismo, cujo entendimento partiria de um modelo reativo do funcionamento mental desconsiderando, consequentemente, a participação da ação nos fenômenos de constituição psíquica (Costa, 2007).

Inicialmente influenciada pela tradição filosófica moderna e pelos modelos científicos da física e da biologia do final do século XIX, Freud (1914/1974) propôs uma descrição da organização narcisista da libido que tomou o investimento em relações de objeto um evento secundário relativamente à necessidade de descarga do excesso de excitação pulsional. Esse modo de compreender o investimento libidinal encerra o ponto central em torno do qual giraram importantes divergências na psicanálise e que congregou esforços direcionados para a elaboração de versões alternativas ao modelo energético-pulsional freudiano. A insatisfação teórica com a versão pulsional freudiana recaiu, sobretudo, na compreensão da dimensão social ou interpessoal dos relacionamentos como um mero efeito da busca por gratificação sexual ou, em outros termos, como um produto da inoperância do mecanismo alucinatório primário gerado pelo organismo para esquivar-se da frustração na tentativa de obter de prazer (Freud, 1923/1974). Em contraste com a perspectiva metapsicológica tradicional, diferentes autores rebateram o pressuposto do interesse no mundo externo como fruto da insuficiência das capacidades de autossatisfação solitária do sujeito e privilegiaram, em contrapartida, a compreensão do processo de formação da identidade levando em conta, sobretudo, a disposição ativa para a constituição de laços afetivos a partir do estabelecimento de proximidades interpessoais (Balint, 1959; Bowlby, 1979/2001; Winnicott, 1945/2000).

Esse primeiro alvo de intensas críticas tangencia o segundo ponto que se pretende destacar, qual seja, o aspecto reativo que incide na gênese da concepção freudiana do eu. Do mesmo modo como o interesse nos objetos é compreendido como o meio privilegiado para a descarga das pulsões erótica e agressiva, depreende-se que não é senão por uma atividade de reação à incapacidade de obter prazer junto aos objetos que a subjetividade pode se constituir. Resumidamente, de acordo com determinadas versões do modelo freudiano, o eu é concebido como um precipitado de representações oriundas do efeito mental das ações que objetos e pessoas exercem sobre o sujeito (Costa, 2007). Herdeira do mecanicismo das filosofias materialistas e racionalistas dos séculos XVIII e XIX, esta perspectiva psicanalítica tomou o sujeito como a consequência do desequilíbrio produzido nos organismos individuais pelas condições ambientais. As "representações 
mentais", compreendidas como o produto da afetação externa, se organizariam de forma a suprir as faltas, desejos e carências que as diversas impressões sensoriais, ao romper o equilíbrio narcísico original, tenderiam a gerar. Dessa perspectiva, o comércio com os objetos e com o outro, longe de ocupar um foco de interesse primário e espontâneo do sujeito, derivaria do efeito da atração do mundo externo sobre um organismo passivo e narcisicamente fechado em si mesmo.

Reproduzindo, portanto, as dificuldades epistemológicas do pensamento cartesiano, tal compreensão das origens do eu se torna lógica e empiricamente incompatível com a percepção do mundo externo, somando-se também à imagem de um ser essencialmente faltoso e reativo às determinações que desequilibram sua condição original. Da perspectiva freudiana, o destino das "pressões da civilização" sobre um indivíduo eminentemente passivo e autocentrado seria, como afirma Cavell, a chave da transformação dos "estados mentais profundamente pessoais, subjetivos e autísticos" característicos do início da vida em "pensamento social" (Cavell, 2006, p.64). De fato, descrevendo a constituição do eu como o subproduto do efeito de frustração sobre as demandas pulsionais ou como resultado representacional do impacto gerado pelas sensações físicas no organismo, a metapsicologia freudiana lança mão do mesmo recurso teórico para explicar tanto a origem da atividade mental - onde o pensamento é concebido como efeito da tendência à descarga barrada pelo princípio da realidade - quanto a gênese das relações objetais.

\section{A origem do eu e a dimensão da alteridade}

As formulações teóricas acerca da vida mental e da gênese do eu têm, contudo, passado por um processo de intensa revisão nos anos recentes. Numa visão que vem ganhando importante espaço na filosofia e na psicologia contemporâneas, supõe-se que um ser desenvolve tanto suas habilidades sócio-cognitivas quanto sua auto-identidade somente quando interagindo num ambiente de trocas interpessoais. Essa "posição intersubjetivista" (Cavell, 2006; Fonagy et al., 2005) - crescentemente defendida em diferentes âmbitos da pesquisa filosófica, psicológica e da prática psicoterápica (Coelho Junior \& Figueiredo, 2003) - questiona precisamente o primado cartesiano da reflexão e do indivíduo solitário e autocentrado como a expressão paradigmática do pensamento humano e da identidade pessoal. Nas últimas décadas, alguns autores têm feito importantes esforços para incorporar pressupostos intersubjetivistas à psicanálise, com o resultado bem-sucedido de contribuir crítica e criativamente para a reformulação de aspectos da metapsicologia freudiana e produzindo, ademais, inovações clínicas de importante alcance (Coelho Junior, 2002). No que tem sido mesmo considerada uma "virada fenomenológica" na psicanálise - em contraste com a "virada linguística" que informou a maioria dos escritos lacanianos das últimas décadas - a valorização das variáveis empáticas entre analista e paciente passaram a concorrer com a ênfase nos processos inconscientes individuais, assim como a dimensão intersubjetiva e relacional vem ganhando terreno relativamente à preponderância do caráter internalista e da dimensão intrapsíquica presentes na teoria e na clínica psicanalíticas (Migone, 2004).
Versões psicanalíticas alternativas ao modelo do eu cartesiano tendem a conferir não apenas maior privilégio à dimensão ambiental nos processos de constituição psíquica, mas tendem também a incluir o outro como um polo fundamental na formação da vida subjetiva. Winnicott (1945/2000), por exemplo, buscou chamar a atenção para a limitação teórica envolvida nas considerações sobre a subjetividade a partir de uma perspectiva eminentemente intrapsíquica do indivíduo, advogando que este não pode ser pensado como fenômeno isolado e apartado do meio que o circunda, mas - o que vale tanto para suas origens quanto para seu desenvolvimento - em permanente conexão com o ambiente. Questionando a sobrevalorização psicanalítica com respeito à dimensão da interioridade psicológica e à noção de representações mentais, Winnicott (1953/1975) dirigiu seu interesse clínico e teórico para os espaços de interação entre o indivíduo e o meio, tendo descrito o psiquismo como o produto da interação do organismo corpóreo individual com seu entorno (Salem, 2007).

$\mathrm{Na}$ filosofia, diversas também foram as reformulações produzidas em torno não apenas da vida mental como um espaço privado e interior, mas da própria formação do eu como um evento auto-engendrado. Autores como Wittgenstein, Mead, Husserl, Merleau-Ponty e Heidegger, dentre outros, buscaram conferir à dimensão da alteridade uma participação central na constituição da vida mental do sujeito, insistindo no caráter público relacional da linguagem, do sentido que conferimos ao mundo e, no limite, da própria atividade perceptiva (Merleau-Ponty, 1945/1999). Em uma palavra, descreveram a interioridade distanciando-se das acepções tradicionais que a ligavam à ideia de uma privacidade ontológica. Guardadas as profundas divergências teóricas e as discordâncias internas que separam e, por vezes, opõem as formulações intersubjetivistas, todas guardam um pressuposto comum: o de que o acesso aos conteúdos mentais e emocionais do próprio sujeito não deriva exclusivamente de um mergulho introspectivo num eu isolado do meio e composto de competências narrativas privadas, mas depende - tanto em sua gênese quanto em seu acesso consciente - da mediação do outro.

A fenomenologia, mais do que qualquer outra corrente do pensamento filosófico, insistiu no caráter intersubjetivo da experiência humana e da formação do eu. Merleau-Ponty (1945/1999, 1942/2002), influenciado por Husserl e por sua compreensão de que toda forma de conhecimento de si e do outro se dá necessariamente por via intersubjetiva, teceu fortes críticas ao subjetivismo e às filosofias da consciência. Distanciando-se da psicologia associacionista das sensações e da psicologia racionalista da consciência, Merleau-Ponty atribuiu ao corpo a mesma capacidade intencional que Husserl imputara à consciência. Em outros termos, compreendeu a intencionalidade não mais como uma faculdade não-corporal ou puramente intelectual e estendeu ao corpo, através da relação pré-reflexiva e imediata com o ambiente, propriedades intencionais tradicionalmente descritas em referencia à vida mental. Tomando a ação não como um processo racional que obedeceria ao estabelecimento de metas conscientes previamente informadas por faculdades cognitivas, Merleau-Ponty defendeu antecipadamente a perspectiva hoje corrente segundo a 
qual percepção e ação formam um conjunto de atividades indissociáveis. Mais do que um organismo passivo sobre o qual incidiriam estímulos exteriores que quando processados pelo sistema cognitivo se converteriam em metas para a ação, ele compreendeu a própria percepção como um fenômeno diretamente ligado à ação corporal (Joas, 1996; Merleau-Ponty, 1945/1999).

De fato, a noção de percepção desenvolvida por MerleauPonty encontra-se na gênese de um modelo de compreensão da vida mental que buscou conceber uma alternativa às posições "materialistas" e "mentalistas". Argumentando que a percepção é o mais fundamental e primordial aspecto da subjetividade humana, Merleau-Ponty advogou que

a partir do momento em que o comportamento é tomado em 'sua unidade' e em seu sentido humano, não se trata mais de uma realidade material nem tampouco de uma realidade psíquica, mas de um conjunto significativo ou de uma estrutura que não pertence propriamente nem ao mundo exterior, nem à vida interior (1942/2002, p.197).

Como já aventado, Merleau-Ponty não equivale a percepção à representação interna de um objeto externo, nem mesmo à ideia de um pensamento reflexivo ou um julgamento sobre o mundo cuja representação se aloca num teatro interno da mente. Para o filósofo, o mundo percebido é o mundo das imbricações inevitáveis e originais entre corpos e coisas, ou entre corpos e outros corpos. Em função da compreensão da reversibilidade que marca a relação entre o corpo e o mundo, Merleau-Ponty descarta uma visão internalista da mente, concebendo a percepção e a significação como atividades oriundas do interjogo entre o homem e o mundo.

Conforme defende Costa (2004), baseando-se em teorias que valorizam a relação do organismo com o ambiente como um fator teórico fundamental, tanto as descrições da psicologia ecológica quanto a própria fenomenologia de Merleau-Ponty apontariam para a presença de um self agente na base da constituição subjetiva. Buscando diferenciá-lo de um self senciente - cuja identidade é tomada como um "precipitado de representações resultante das 'reações' físico-mentais do organismo aos apelos do ambiente" - Costa descreve o "self agente" como uma instância originalmente ativa, "normativa e valorativa" desde o início. Em outros termos, o eu não é aqui compreendido como um "efeito mental das ações que objetos e pessoas exercem sobre o sujeito", mas um produto da ação corporal do organismo sobre o ambiente. Deriva deste modelo, por exemplo, a compreensão de que as emoções são modos particulares de perceber e agir no mundo, e não apenas uma experiência privada e acessível apenas ao sujeito por uma habilidade introspectiva. Dessa perspectiva, mais do que uma "realidade interna" ou fato psíquico escondido atrás de um gesto, a emoção corresponde a um evento reconhecível em formas de conduta publicamente acessíveis.

O pressuposto básico de uma continuidade fenomenológica entre o mundo físico e o mental fez Merleau-Ponty opor formas de compreensão intelectuais a um tipo de compreensão que chamou de existencial, posto não envolver exclusivamente atributos mentais. Conhecimento e compreensão são, para ele, capacidades para a ação de um agente cuja relação com o mundo é eminentemente prática. Do mesmo modo, condutas perceptivas, linguísticas e afetivas não são adquiridas pela reflexão, como o produto de uma consciência desencarnada, e, sim, o resultado de modos práticos de estar no mundo. Como afirma Crossley,

o 'objeto', não menos do que o 'sujeito' da percepção, é revelado como o resultado do processo perceptivo e a percepção mostra ser um processo ativo no qual o organismo interroga seu entorno, guiado por sensibilidades biológicas e esquemas comportamentais e perceptuais, criando então para si um 'meio' subjetivo" (Crossely, 2001, p.71).

\section{Corporeidade e ação nos processos de formação do eu}

Posições intersubjetivistas e a consideração da dimensão corporal nos processos de formação do eu disseminaram-se para além da fenomenologia e hoje informam numerosos modelos de compreensão da vida subjetiva. De fato, nas últimas décadas, a perspectiva fenomenológica tornou-se uma referência teórica incontornável para as elaborações recentes da psicologia do desenvolvimento, da filosofia da mente e das neurociências cognitivas na compreensão dos processos de constituição psíquica (Bermudez, Marcel, \& Eilan, 2001; Gallagher \& Meltzoff, 1996). Como vimos, ao tomar como objeto de estudo não mais o sujeito e o corpo como elementos ontologicamente distintos, mas o chamado "sujeito corporal" (Barbaras, 1992), a fenomenologia redimensionou o valor da narratividade e do pensamento conceitual e reflexivo na experiência do eu, incluindo no horizonte epistemológico dos estudos sobre a vida subjetiva três elementos fundamentais, a saber, a valorização da relação entre o organismo e ambiente, o papel central ocupado pela corporeidade na organização da vida subjetiva, e a importância da ideia de ação nos modelos da vida mental.

O conceito de ação e sua relação com a corporeidade tornaramse fatores nodais nos modelos explicativos contemporâneos dos processos de formação do eu. Comparativamente à pouca expressividade do termo na teoria psicanalítica - representada por suas referências fragmentadas na obra de Freud e pelas breves tentativas pós-freudianas de lhe conferir um estatuto teórico consistente (Perron, 2005) -, a preocupação com o conceito de ação vem ganhando destaque em estudos recentes sobre a subjetividade $^{3}$. De fato, a partir das investigações empíricas da psicologia do desenvolvimento, do cognitivismo e de releituras contemporâneas da fenomenologia, uma importância considerável tem sido outorgada à participação da corporeidade e da ação intencional nos processos de formação do eu.

De modo geral, tais disciplinas têm contribuído para a operação de um deslocamento do valor tradicionalmente outorgado ao eixo da representação para o eixo da ação como fator determinante dos processos de constituição do eu. Estudos empíricos realizados sob os auspícios de novos paradigmas experimentais, bem como das novas técnicas de registro e observação do comportamento infantil, têm demonstrado que bebês possuem capacidades perceptuais, de aprendizado e representacionais notavelmente ricas, além de uma preparação para interagir com o mundo físico e social bastante prematuras (Fonagy et al. 2005; Rochat, 2004; Tomasello, 2000). No que 
poderia ser descrito como uma revolução na compreensão das capacidades precoces dos bebês, tais pesquisas têm alterado radicalmente o que se pensava até duas décadas atrás, colaborando para a construção de uma imagem da vida infantil notavelmente mais rica e mais complexa do que aquela até então descrita por estudiosos do desenvolvimento. Testemunhando a capacidade de bebês para entrar em sintonia afetiva com outros significativos (Stern, 2003; Trevarthen, 1980), bem como a habilidade para imitar gestos e ações do outro desde as primeiras horas de vida (Meltzoff \& Moore, 1983), a maioria das pesquisas atuais sobre o desenvolvimento infantil corrobora a fenomenologia não apenas ao tomar a intersubjetividade como um fato presente desde os primórdios da vida, mas também ao atrelar o surgimento da subjetividade à ação corporal intencional (Rochat, 2007).

Influenciados, sobretudo, pela teoria ecológica da percepção elaborada por James Gibson nos anos setenta, autores como Neisser (1988), Rochat (2002, 2004) e Tomasello (2000), entre outros, passaram a dar maior ênfase à relação entre a percepção e a ação como a fonte de um primeiro senso de self nos bebês ${ }^{4}$. Diferentemente de Piaget (1987), que condicionou a experiência da "consciência pessoal sentida como um 'eu" à emergência das capacidades simbólicas da criança, tais autores passaram a defender a existência de outras modalidades de "eu" que, ainda que distintas de uma vivência conceitual ou reflexiva, seriam claramente identificáveis nas primeiras manifestações comportamentais da criança. Dados empíricos parecem sugerir que, paralelamente a um eu categorial e representacional cuja organização da identidade se dá através de narrativas linguísticas da própria experiência nas quais o sujeito se vê como protagonista dos eventos vividos - subjaz um eu experiencial que corresponde a uma forma primitiva e pré-reflexiva de autoconsciência fenomenal que acompanha sensações corporais, estados emocionais e conteúdos cognitivos desde o nascimento (Neisser, 1988) $)^{5}$. Contrariando, portanto, o fato de que por muito tempo o estudo do eu como um "agente mental" priorizou os aspectos conceituais presentes na sua formação, diversos pesquisadores têm hoje investigado outros níveis de expressão e gênese do eu (Fonagy et al., 2005).

Diferentemente de versões metapsicológicas que condicionaram a autoconsciência seja à relação especular imaginária com o outro, seja ao desenvolvimento das capacidades simbólicas do sujeito, tais autores defendem a existência de outras modalidades de eu, identificáveis já nas primeiras manifestações comportamentais da criança. Sem querer fazer coincidir a auto-percepção com a gestação do autoconhecimento reflexivo tomam, no entanto, a matriz corporal como um fundamento para as duas. Pelo ajuste imediato do organismo com o meio, a auto-percepção se torna um elemento sempre presente em condições normais de funcionamento psíquico e um fator básico na constituição e delimitação dos contornos egóicos. Os autores acima citados, baseando-se em estudos experimentais que rompem com a noção tradicional a respeito das capacidades interativas dos bebês, centram seus argumentos prioritariamente em dois aspectos. Advogam, em primeiro lugar, em favor da existência nas crianças de um equipamento inato para diferenciar-se do mundo e, em segundo, da capacidade que desde cedo demonstram para comportar-se diferencialmente com relação a pessoas ou objetos.

Neisser (1988) soma importantes argumentos para a defesa do primeiro aspecto. Esse autor apoia a capacidade de diferenciação precoce entre o bebê e o mundo externo na hipótese de que, antes mesmo da formação de um senso explícito e reflexivo do eu, uma série de gradações relacionadas à auto-percepção do recém-nascido podem ser depreendidas da interação que estabelece com o meio. Pressupondo que desde o nascimento o bebê manifesta um conhecimento implícito do próprio corpo como uma entidade diferenciada dos outros objetos do ambiente, esse autor denomina tal experiência de self ecológico. A agência ocupa aqui peça central, já que é fundamentalmente por meio da discriminação de informações perceptivas derivadas das alterações produzidas no ambiente e no próprio corpo pela ação corporal que o bebê desenvolve seu primeiro senso de self.

Rochat $(2002,2004)$ sugere que aos dois meses as crianças já passam a demonstrar uma atenção especial dirigida às conseqüências de suas ações no ambiente. Assumem uma atitude exploratória com relação às alterações que produzem no entorno por meio de uma "atitude contemplativa" (contemplative stance) que, por sua vez, intensifica a experiência do self ecológico. Recém-nascidos passam a explorar sistematicamente a relação entre suas ações e seus efeitos no ambiente ou em si mesmos buscando, por exemplo, verificar a coerência entre um estímulo auditivo e seu esforço proprioceptivo. Assim, uma criança que involuntariamente chuta pela primeira vez um móbile ao seu alcance, ou que repete gestos simples como atravessar seu campo visual com a mão, e que passa progressivamente a repeti-las de modo mais sistemático, estaria explorando seus recursos no ambiente e gerando informações sensoriais necessárias para especificar seu próprio self. Modos de percepção intermodal isto é, que relacionam informações de diferentes modalidades da percepção - ocupam, portanto, um papel central na habilidade infantil para diferenciar-se do meio. É pela associação entre estímulos perceptivos diferentes - por exemplo, pela relação entre o movimento corporal realizado (propriocepção) e um consequente som ou efeito visual produzido - que o bebê passa a experimentar seu senso gradual de interação ecológica com o ambiente. As diversas formas pelas quais o recém-nascido pode inspecionar o seu corpo em ação - seja alterando o ambiente, seja a si mesmo por meio de sensações proprioceptivas - permitem que se experimente desde muito cedo como um organismo distinto dos outros objetos. Aqui “a propriocepção, em conjunção com outros sistemas perceptuais, é a modalidade do self por excelência" (Rochat \& Striano, 2000, p.517).

O segundo argumento que concorre para a mudança recente na compreensão das habilidades interativas de bebês diz mais especificamente respeito às respostas comportamentais geradas quando em contato com o mundo social. Paralelamente ao senso de self oriundo de uma experiência perceptiva imediata do corpo em ação, Neisser (1988) destaca outra modalidade implícita de auto-percepção: o self interpessoal. Se é do mundo físico que a criança depreende as informações para seu senso de self ecológico, é fundamentalmente no ambiente "social" que encontra os elementos que ajudarão a compor seu self 
interpessoal. Nesse caso, é por meio das primeiras experiências com outros significativos que o bebê obtém informações nas quais baseia essa modalidade de sua experiência precoce de self. No contexto das trocas imediatas e pré-reflexivas verificadas no "face-a-face" próprio aos primeiros meses de vida o recémnascido não apenas reage aos anseios comunicativos do outro, mas também se serve dos efeitos de seus comportamentos intencionais como dados relativos ao próprio self.

\section{Considerações Finais}

Os estudos e as inferências sobre a formação do eu oriundas da psicologia do desenvolvimento, ainda que consideravelmente distantes da tradição psicanalítica, vêm aos poucos ocupando crescente espaço na pesquisa clínica e conceitual de alguns psicanalistas contemporâneos (Fonagy, 2004; Roussillon, 2002; Stern, 2003). Buscando superar o fosso que diferenças epistemológicas importantes - aliadas a certa dose de preconceito de ambas as partes - impõem a possíveis interfaces entre tais saberes, alguns autores têm tentado estreitar os frágeis laços que os mantêm em diálogo e servir-se deste encontro para propor - no caso da psicanálise - certas reformulações à metapsicologia, à teoria da mente psicanalítica ou à compreensão de determinados fenômenos psicopatológicos (Fonagy et al., 2005; Imbasciati, 2007; Roussillon, 2004).

Foi neste sentido que se buscou aqui examinar dois modelos prevalentes da formação do eu focando, de um lado, uma versão psicanalítica cuja ênfase recai em aspectos mentalistas e internalistas da vida psíquica e, de outro, sua descrição efetuada por autores da psicologia do desenvolvimento e da fenomenologia como um agente corporificado e dotado de um senso rudimentar de eu oriundo de competências sóciocognitivas presentes desde muito cedo no desenvolvimento infantil. Procurando enfatizar o domínio da corporeidade e da ação na formação do eu, apontamos para um tipo de descrição da vida mental alternativa àquela propugnada pela epistemologia racionalista dos séculos XVIII e XIX, e que tanto marcou os primórdios da teoria psicanalítica e suas inferências sobre a vida mental. Considerando, no entanto, os impasses teóricos desta perspectiva e as repercussões clínicas derivadas das transformações sócio-culturais aqui repertoriadas como produto do enfraquecimento do valor cultural da interioridade psicológica, entendemos que os novos modelos de formação do eu propostos pelas disciplinas acima analisadas podem fornecer indícios importantes para novas proposições metapsicológicas. Nessa primeira aproximação, além de pretendermos proporcionar a ampliação e o aprofundamento da fundamentação teórica que permita a articulação entre a psicanálise e linhas psicológicas experimentais e cognitivas, aspiramos chamar a atenção para novos modos de compreensão do eu capazes de levantar questões relevantes sobre o modo de funcionamento das modernas formas de psicopatologia ligadas aos distúrbios do corpo e da imagem do eu.

\section{Referências Bibliográficas}

Balint, M. (1959). Thrills and Regressions. London: The Hogarth Press.
Barbaras, R. (1992). De la phénoménologie du corps à l'ontologie de la chair In J.C. Goddard \& M. Labrune (Orgs.), Le corps (pp. 207-250). Paris: Vrin Éditions.

Bauman, Z. (1998). O mal-estar na pós-modernidade. Rio de Janeiro: Jorge Zahar Editor.

Bermudez, J. L., Marcel, A., \& Eilan, N. (2001). The body and the self. Cambridge: Press.

Bezerra, B. (2002). O ocaso da interioridade e suas repercussões sobre a clínica. In C. A. Plastino (Org.), Transgressões (pp. 229-239). Rio de Janeiro: Contra-Capa.

Bowlby, J. (2001). Formação e rompimento dos laços afetivos. São Paulo: Martins Fontes. (Texto original publicado em 1979)

Cavell, M. (2006). Becoming a subject: reflections in philosophy and psychoanalysis. New York: Oxford University Press.

Coelho Junior, N. E. (2002). Intersubjetividade: conceito e experiência em psicanálise. Psicologia Clínica, 14(1), 61-74.

Coelho Junior, N. E., \& Figueiredo, L. C. (2003). Patterns of intersubjectivity in the constitution of subjectivity: dimensions of otherness. Culture \& Psychology, 9(3), 193-208.

Costa, J.F. (2004). O vestígio e a aura: corpo e consumismo na moral do espetáculo. Rio de Janeiro: Garamond.

Costa, J.F. (2007). O Risco de cada um e outros ensaios de psicanálise e cultura. Rio de Janeiro: Garamond.

Crossley, N. (2001). The social body: habit, identity and desire. London: Sage Publications.

Eagle, M. N. (1984). Recent developments in psychoanalysis. New York: Harvard University Press.

Ferenczi, S. (s.d) Escritos Psicanalíticos 1909 - 1933. Rio de Janeiro: Taurus.

Figueiredo, L. C. M. (1999). A invenção do psicológico: quatro séculos de subjetivação (1500-1900). São Paulo: Escuta e Educação.

Fonagy, P. (2004). Théorie de l'attachement et psychanalyse. Paris: Éditions Érès.

Fonagy, P., Gergely, G., Jurist, E., \& Target, M. (2005). Affect regulation, mentalization and the development of the self. London: Karnac.

Freud, S. (1974). Sobre o narcisismo: uma introdução. In S. Freud, Edição standard brasileira das obras psicológicas completas de Sigmund Freud (Volume 14, pp. 89-119). Rio de Janeiro Imago. (Texto original publicado em 1914)

Freud, S. (1974). O Ego e o Id. In S. Freud, Edição standard brasileira das obras psicológicas completas de Sigmund Freud (Volume 19, pp. 23-83). Rio de Janeiro: Imago. (Texto original publicado em 1923)

Gallagher, S., \& Meltzoff, A. (1996). The earliest sense of self and others: Merleau-Ponty and recent developmental studies. Philosophical Psychology, 9, 213-236.

Green, A. (2002). Idées directrices pour une psychanalyse contemporaine. Paris: Presses Universitaires de France.

Imbasciati, A. (2007). Neurosciences et Psychanalyse: pour une nouvelle metapsychologie. Revue Française de Psychanalyse, 21(2), 455-477.

Joas, H. (1996). The creativity of action. Chicago: University of Chicago Press.

Lasch, C. (1983). A cultura do narcisismo: a vida americana numa era de esperanças em declínio. Rio de Janeiro: Imago.

Lipovetsky, G. (1983). A era do vazio: ensaio sobre o individualismo contemporâneo. Lisboa: Relógio d'Água.

Meltzoff, A., \& Moore, K. (1983). Newborn infants imitate adult facial gestures, Child Development, 54(3), 702-709.

Merleau-Ponty, M. (1999). A fenomenologia da percepção. São Paulo: Martins Fontes. (Texto original publicado em 1945)

Merleau-Ponty, M. (2002). La structure du comportement. Paris: Presses Universitaires de France. (Texto original publicado em 1942)

Migone, P. (2004). Editoriale. Psicoterapia e Scienze Umane, 97, 83-88. Recuperado de http://www.psychomedia.it/pm/modther/probpsiter/ruoloter/ rt97-04.htm 
Neisser, U. (1988). Five kinds of self-knowledge. Philosophical Psychology, $1,35-59$.

Perron, R. (2005). Acte, Action. In A. Mijolla (Org.), Dictionaire International de la Psychanalyse (pp. 14-15). Paris: Hachette.

Piaget, J. (1987). O nascimento da inteligência na criança. Rio de Janeiro: LTC.

Rochat, P. (2002). Naissance de la co-conscience. Revue Intellectica, 1(34), 99-123.

Rochat, P. (2004). The infant's world. Cambridge: Harvard University Press.

Rochat, P. (2007). Intentional action arises from early reciprocal exchanges. Acta

Psychologica, 124, 8-25.

Rochat, P., \& Striano, T. (2000). Perceived self in infancy. Infant Behaviour \& Development, 23, 513-530.

Roudinesco, E. (2000). Por que a psicanálise? Rio de Janeiro: Jorge Zahar.

Roussillon, R. (2002). Le plaisir et la répétition, Paris: Dunod.

Roussillon, R. (2004). La dépendance primitive et l'homosexualité primaire 'en double'. Revue Française de Psychanalyse, 68(2), 421-439.

Salem, P. (2007). Reflexões sobre confiança e hábito em D.W. Winnicott e J. Dewey. In B.

Bezerra Jr \& F. Ortega (Orgs.), Winnicott e seus interlocutores (pp. 166-198).
Rio de Janeiro: Relume-Dumará.

Sennett, R. (1999). A corrosão do caráter: conseqüencias pessoais do trabalho no novo capitalismo. Rio de Janeiro: Record.

Stern, D. (2003). Le monde interpersonnel du bébé. Paris: Presses Universitaires de France.

Taylor, C. (1994). As fontes do self: a construção da identidade moderna. São Paulo: Edições Loyola.

Tomasello, M. (2000). The cultural origins of human cognition. Cambridge: Harvard University Press

Trevarthen, C. (1980). The foundations of intersubjectivity: development of interpersonal and cooperative understanding in infants. In D. R. Olson (Org.), The social foundations of language and thought: essays in honor of Jerome Bruner (pp. 316-341). New York: Norton.

Winnicott, D.W. (2000) Desenvolvimento emocional primitivo. In D. W. Winnicott, Da pediatria à psicanálise (pp. 218-232), Rio de Janeiro: Imago. (Texto original publicado em 1945)

Winnicott, D.W. (1975) Objetos transicionais e fenômenos transicionais. In D. W. Winnicott, O brincar e a realidade (pp. 13-44). Rio de Janeiro: Imago. (Texto original publicado em 1953). 
1. Seguindo a sugestão terminológica de Costa (2004), estaremos considerando que dentro da grade dos transtornos da imagem corporal estão incluídos, por exemplo, os distúrbios alimentares, as práticas compulsivas ligadas à modificação corporal bem como as ansiedades de exposição manifestadas na síndrome do pânico e nas fobias sociais. Já os abusos na exploração das sensações corporais incluem, sobretudo, as dependências químicas de drogas lícitas ou ilícitas.

2. É importante deixar claro que, ainda que a literatura psicanalítica indique claramente que já no final da década de trinta alguns autores tenham proposto importantes reformulações à técnica analítica - como a chamada "técnica ativa" desenvolvida por Sandor Ferenczi (s/d) -, pretende-se aqui salientar que foi sobretudo a partir da segunda metade do século XX que este movimento tomou nova e intensa proporção. Vale igualmente notar que o interesse que certos psicanalistas passaram a dedicar a uma grade nosológica em certa medida distinta da tradicional não significa afirmar que o estudo, o tratamento e as elaborações sobre a neurose tenham se enfraquecido ou deixado de constituir o eixo central da psicanálise.

3. Episodicamente citado por Freud, o termo é mais freqüentemente usado na teoria psicanalítica por meio do conceito de ação-específica, significando uma resposta adequada do organismo a estímulos internos ou externos, com o objetivo de fazer cessar a busca pela satisfação da necessidade ou esquivar-se de uma situação penosa. Contudo, essa acepção parece reproduzir a compreensão da atividade corporal como sendo eminentemente automática e reflexa, distanciandose da perspectiva recentemente defendida pela fenomenologia e pela psicologia do desenvolvimento de um corpo dotado de capacidades intencionais.

4. A teoria ecológica da percepção desenvolvida por James Gibson tem influenciando uma vasta corrente de disciplinas psicológicas e filosóficas nas últimas décadas. Em termos resumidos, defende a idéia de que a percepção dos recursos do ambiente por parte do indivíduo é correlata e contemporânea no desenvolvimento à emergência da autopercepção. Percebendo os objetos à sua volta e explorando-os por meio do movimento corporal, os indivíduos depreendem informações que especificam tanto a propriedade dos objetos quanto a si mesmos.

5. Como deverá ficar claro à seguir, Neisser (1988) supõe uma forma muito precoce de self, diretamente ligada às experiências corporais do bebê. Baseado em informações perceptivas derivadas da ação corporal, esse senso de self complexifica-se com o desenvolvimento, ganha novas qualidades, mas, de fato, é compreendido como um fator presente desde o início da vida, e que responde pela experiência precoce de diferenciação entre o bebê e o ambiente. Já Winnicott, ainda que recuperado neste artigo como um autor que rompe com pressupostos psicanalíticos tradicionais - como a ênfase nas representações mentais e na dimensão intrapsíquica - compreende a constituição subjetiva de uma perspectiva que contrasta com a de Neisser. Para Winnicott, um estado de continuidade entre o eu e o outro marca as primeiras experiências do bebê, cujo senso de self desenvolve-se apenas a partir de um gradual processo de diferenciação do ambiente. Para maiores detalhes ver Winnicott (1945/2000).

Pedro Salem, doutor em Saúde Coletiva pelo Instituto de Medicina Social da Universidade do Estado do Rio de Janeiro (IMS/UERJ), é Pós-Doutorando no Departamento de Psicologia Experimental (PSE) do Instituto de Psicologia da Universidade de São Paulo. Endereço para Correspondência: Avenida São Paulo Antigo, 339/101 - Real Parque. São Paulo - CEP: 5684010. Tels: (21) 8216-5055. E-mail: pedrosalem@terra.com.br Nelson Ernesto Coelho Junior, doutor em Psicologia Clínica pela Pontifícia Universidade Católica de São Paulo, é professor do Instituto de Psicologia da Universidade de São Paulo. 